\title{
Pulsatile Insulin Release from Mouse Islets Occurs in the Absence of Stimulated Entry of $\mathrm{Ca}^{2+}$
}

\author{
Johanna Westerlund, Bo Hellman, and Peter Bergsten \\ Department of Medical Cell Biology, University of Uppsala, S-751 23 Uppsala, Sweden
}

\begin{abstract}
Pancreatic islets are known to respond to a raise of the glucose concentration with $\mathrm{Ca}^{2+}$-induced 2-3-min pulses of insulin release. The reports of cyclic variations of circulating insulin in the fasting state made it important to explore whether insulin release is also pulsatile in the absence of stimulated entry of $\mathrm{Ca}^{2+}$. Individual pancreatic islets were isolated from a local colony of $o b / o b$ mice and perifused under conditions allowing dual wavelength recordings of the cytoplasmic $\mathrm{Ca}^{2+}$ concentration $\left(\left[\mathrm{Ca}^{2+}\right]_{i}\right)$ with fura-2 and measurements of insulin with ELISA technique. At $3 \mathrm{mM}$ of glucose, $\left[\mathrm{Ca}^{2+}\right]_{i}$ remained at a stable low level, but insulin was released in pulses with a frequency of $0.41 \pm 0.02 \mathrm{~min}^{-1}$, determined by Fourier transformation of original and autocorrelated data. Pulses of basal insulin release were also seen when glucose was omitted and $1 \mu \mathrm{M}$ clonidine or 400 $\mu \mathrm{M}$ diazoxide was added to a glucose-free medium. The results indicate that pulsatile insulin release can be generated in the absence of stimulated entry of $\mathrm{Ca}^{2+}$. A tentative explanation for this phenomenon is inherent fluctuations in the ATP production of the $\beta$ cells. (J. Clin. Invest. 1996. 97: 1860-1863.) Key words: ATP • cytoplasmic $\mathrm{Ca}^{2+} \cdot$ glucose • clonidine $\cdot$ diazoxide
\end{abstract}

\section{Introduction}

The concentration of insulin in blood varies in a periodic fashion, reflecting pulsatile release from the pancreas $(1,2)$. An important step towards understanding the mechanisms for insulin release was the observation that isolated $\beta$ cells respond to a glucose stimulus with slow oscillations of cytoplasmic $\mathrm{Ca}^{2+}$ (3). Subsequent analyses revealed that these oscillations can be attributed to periodic depolarization with resulting entry of $\mathrm{Ca}^{2+}$ via voltage-dependent channels (4). It is now well established that the glucose-induced pulses of insulin release from an isolated islet result from a synchronization of the oscillatory $\mathrm{Ca}^{2+}$ signals in the $\beta$ cells $(5,6)$.

The oscillatory $\mathrm{Ca}^{2+}$ response to glucose requires that the concentration of the sugar is raised above a threshold value characteristic for the individual $\beta$ cell (4). This behavior contrasts with the in vivo situation with periodic variations of cir-

Address correspondence to Dr. Peter Bergsten, Department of Medical Cell Biology, University of Uppsala, Box 571, S-751 23 Uppsala, Sweden. Phone: 46-18-17 49 23; FAX: 46-18-17 40 59; E-mail: Peter. Bergsten@medcellbio.uu.se

Received for publication 27 November 1995 and accepted in revised form 5 February 1996

J. Clin. Invest.

(C) The American Society for Clinical Investigation, Inc.

0021-9738/96/04/1860/04 \$2.00

Volume 97, Number 8, April 1996, 1860-1863 culating insulin also under fasting conditions $(1,2)$. It was recently reported that at least $70 \%$ of the insulin in the portal vein from dogs starved overnight is secreted in discrete pulses (7). The observation that in vivo release of insulin appears to be cyclic under basal conditions raises the question of whether signals other than $\mathrm{Ca}^{2+}$ may generate insulin pulses. The present study provides evidence that this is the case by demonstrating that insulin pulses can be generated also in the absence of stimulated entry of $\mathrm{Ca}^{2+}$.

\section{Methods}

Materials. Reagents of analytical grade and deionized water were used. Collagenase, Hepes, and bovine serum albumin (fraction V) were obtained from Boehringer Mannheim GmbH (Mannheim, Germany). Tetramethylbenzidine and insulin peroxidase came from Sigma Chemical Co. (St. Louis, MO). The rat insulin standard was from Novo Nordisk (Bagsvaerd, Denmark). IgG-certified microtiter plates were purchased from Nunc (Roskilde, Denmark). Diazoxide and clonidine were gifts from the Schering Corp. (Kenilworth, NJ) and Boehringer Ingelheim (Ingelheim/Rhein, Germany), respectively. The mouse insulin antibodies were raised in our laboratory from guinea pigs.

General design of experiments. Islets were isolated with collagenase from $o b / o b$ mice taken from a local colony (8) and starved overnight. When used for measurements of the cytoplasmic $\mathrm{Ca}^{2+}$ concentration $\left(\left[\mathrm{Ca}^{2+}\right]_{\mathrm{i}}\right),{ }^{1}$ islets were cultured overnight in RPMI 1640 medium containing $5.5 \mathrm{mM}$ glucose and supplemented with $10 \%$ fetal calf serum. Subsequent experiments were performed with a medium supplemented with $1 \mathrm{mg} / \mathrm{ml}$ albumin and containing (in $\mathrm{mM}$ ): 125 $\mathrm{NaCl}, 5.9 \mathrm{KCl}, 1.2 \mathrm{MgCl}_{2}, 1.28 \mathrm{CaCl}_{2}$, and $25 \mathrm{Hepes}$, titrated to $\mathrm{pH} 7.4$ with $\mathrm{NaOH}$.

Measurements of cytoplasmic $\mathrm{Ca}^{2+}$. Islet $\left[\mathrm{Ca}^{2+}\right]_{\mathrm{i}}$ was measured essentially adhering to a previous protocol (6). A single islet was loaded with the acetoxymethyl ester of fura- $2(2 \mu \mathrm{M})$ during $40 \mathrm{~min}$ in the presence of $3 \mathrm{mM}$ glucose. After rinsing, the islet was allowed to attach to the central part of a coverslip coated with poly-L-lysine. The coverslip was used as part of a small perifusion chamber, which was placed on the stage of an inverted microscope (Nikon Diaphot) within a climate box maintained at $37^{\circ} \mathrm{C}(6,9)$. The microscope was equipped for epifluorescence fluorometry with a $400-\mathrm{nm}$ dichroic mirror, a $\times 100$ UV fluorite objective, and a photomultiplier. The islet was perifused at a rate of $150-200 \mu \mathrm{l} \cdot \mathrm{min}^{-1}$, and $\left[\mathrm{Ca}^{2+}\right]_{\mathrm{i}}$ was recorded with dual wavelength fluorometry with excitation at 340 and $380 \mathrm{~nm}$ and emission at $510 \mathrm{~nm}(10)$.

Measurements of insulin release. A single islet was placed in a $10-\mu \mathrm{l}$ chamber and perifused at $37^{\circ} \mathrm{C}$ in the presence or absence of $3 \mathrm{mM}$ glucose. A flow rate of $150-200 \mu \mathrm{l} \cdot \mathrm{min}^{-1}$ was established using a peristaltic pump. After $60 \mathrm{~min}$ of introductory perifusion, the perifusate was collected in 20-s fractions and immediately cooled on ice. The fractions were analyzed for insulin by a competitive ELISA with the insulin-capturing antibody immobilized directly in the solid phase $(11,12)$. Amounts of insulin down to 100 attomol were calculated from linear standard curves in semilogarithmic plots (12). The rate of

1. Abbreviation used in this paper: $\left[\mathrm{Ca}^{2+}\right]_{\mathrm{i}}$, cytoplasmic $\mathrm{Ca}^{2+}$ concentration. 


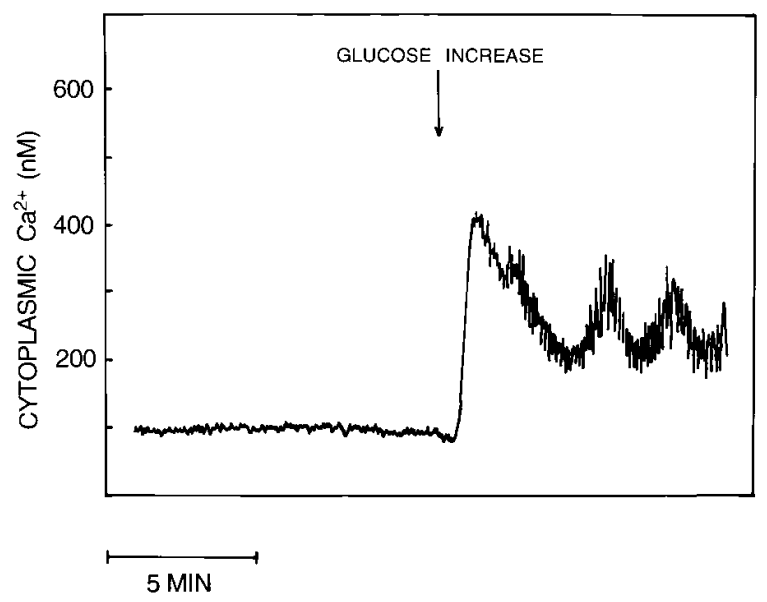

Figure 1. Effects of glucose on the cytoplasmic $\mathrm{Ca}^{2+}$ concentration in an individual islet. The arrow indicates the time when glucose was raised from 3 to $11 \mathrm{mM}$. Results are representative of seven experiments.

insulin release was normalized to dry weight after freeze drying and weighing the islets on a quartz fiber balance. The islet weights ranged between 5 and $10 \mu \mathrm{g}$ to ensure that the amount of insulin in each fraction was within the linear part of the standard curve.

A prerequisite for measuring the periodicity of insulin release with the technique used is that the fractions analyzed have a fairly constant volume. Photometric measurements of methylene blue added to the perifusion medium made it possible to ascertain that this criterion was fulfilled. It was also tested whether pressure changes induced by the pump initiated variations in the amounts of insulin released. Similar results were obtained by using different types of pumps placed before or after the chamber or when simply using gravity as the driving force for the perifusion medium.

Data analysis. The presence of insulin pulses and their frequencies were assessed from power spectra obtained by Fourier transformation of original and autocorrelated data. In general, the relevant peak was clearly and uniquely identifiable. In all cases the corresponding area was more than three times higher than the adjacent parts of the spectrum, neglecting the extreme low frequency components derived from the drift. Average secretory rates were calculated

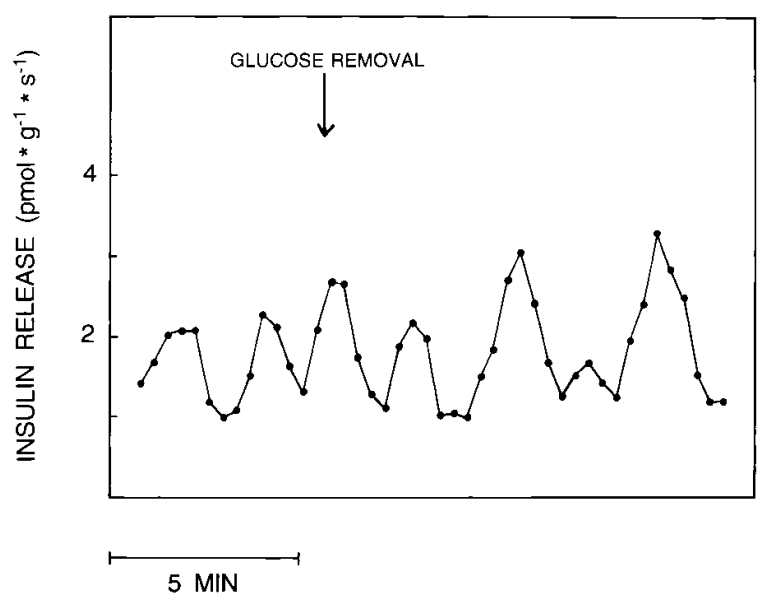

Figure 2. Insulin release from an individual islet in the presence and absence of $3 \mathrm{mM}$ glucose. The arrow indicates the time when glucose was removed from the perifusion medium. Results are representative of 14 experiments.
Table I. Insulin Release from Single Pancreatic Islets in the Presence and Absence of $3 \mathrm{mM}$ Glucose

\begin{tabular}{|c|c|c|c|}
\hline \multirow{2}{*}{$\begin{array}{c}\begin{array}{c}\text { Introductory } \\
\text { perifusion }\end{array} \\
\text { Glucose }\end{array}$} & \multirow{2}{*}{$\frac{\text { Perifusion }}{\text { Glucose }}$} & \multicolumn{2}{|c|}{ Characteristics of insulin release } \\
\hline & & Average rate & Frequency \\
\hline$m M$ & $m M$ & $\mathrm{pmol} \cdot \mathrm{g}^{-1} \cdot \mathrm{s}^{-1}$ & $\min ^{-1}$ \\
\hline 3 & 3 & $2.8 \pm 0.6(14)$ & $0.41 \pm 0.02(14)$ \\
\hline 3 & 0 & $3.2 \pm 0.7(14)$ & $0.43 \pm 0.03$ \\
\hline 0 & 0 & $5.2 \pm 0.7 *(5)$ & $0.30 \pm 0.07(5)$ \\
\hline
\end{tabular}

After $60 \mathrm{~min}$ of introductory perifusion with or without $3 \mathrm{mM}$ glucose, the release of insulin was measured during $20 \mathrm{~min}$ in the presence or absence of $3 \mathrm{mM}$ glucose. When glucose was omitted during the introductory perifusion, the sugar was also absent during a preceding normalization period of $90 \mathrm{~min}$. Mean values \pm SEM for the number of experiments are shown within parenthesis. $* P<0.01$ compared with islets exposed to $3 \mathrm{mM}$ glucose during the introductory period and subsequently perifused in the absence of the sugar.

using moving averages of three consecutive sample points. Analyses of the frequencies and average rates were performed with the Igor software (Wave Metrics Inc., Lake Oswego, OR).

Statistical analysis. Results are presented as means \pm SEM. Differences in secretory rates were evaluated with Student's $t$ test.

\section{Results}

Islet $\left[\mathrm{Ca}^{2+}\right]_{\mathrm{i}}$ was nonfluctuating and low $(101 \pm 11 \mathrm{nM}, n=7)$ in the presence of $3 \mathrm{mM}$ glucose (Fig. 1). Increase of the glucose concentration to $11 \mathrm{mM}$ resulted in characteristic oscillations of the cytoplasmic $\mathrm{Ca}^{2+}$ concentration with a frequency of $0.40 \pm 0.03 \mathrm{~min}^{-1}(n=6)$.

The existence of pulsatile insulin release was assessed from power spectra obtained by Fourier transformation of original and autocorrelated data (Fig. 2). In the presence of $3 \mathrm{mM}$ glucose, the pulse frequency was $0.41 \pm 0.02 \mathrm{~min}^{-1}$ and the average secretory rate was $2.8 \pm 0.6 \mathrm{pmol} \cdot \mathrm{g}^{-1} \cdot \mathrm{s}^{-1}$ (Table I). Neither

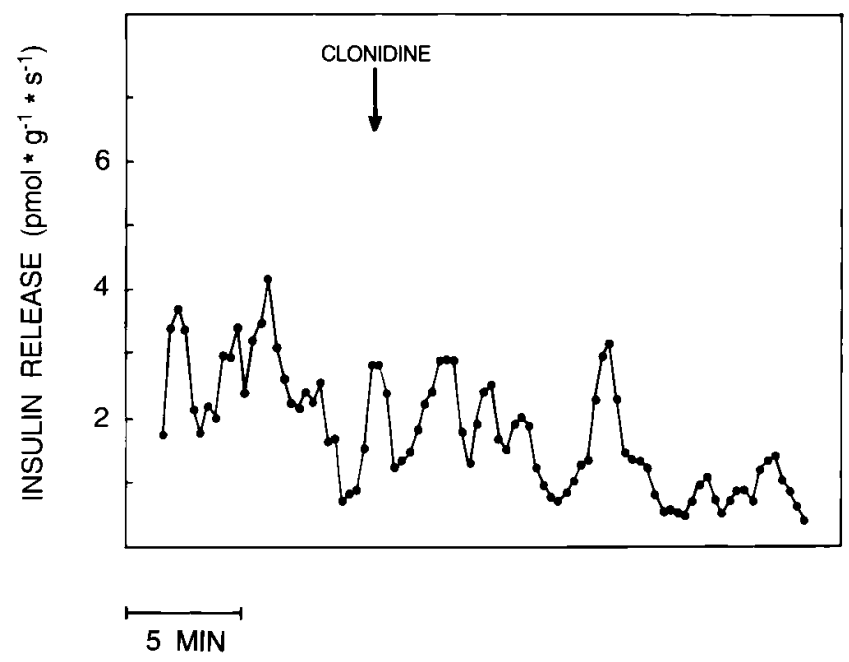

Figure 3. Effects of clonidine on insulin release from an individual islet in the absence of glucose. The arrow indicates the time when $1 \mu \mathrm{M}$ clonidine was added to the perifusion medium. Results are representative of five experiments. 


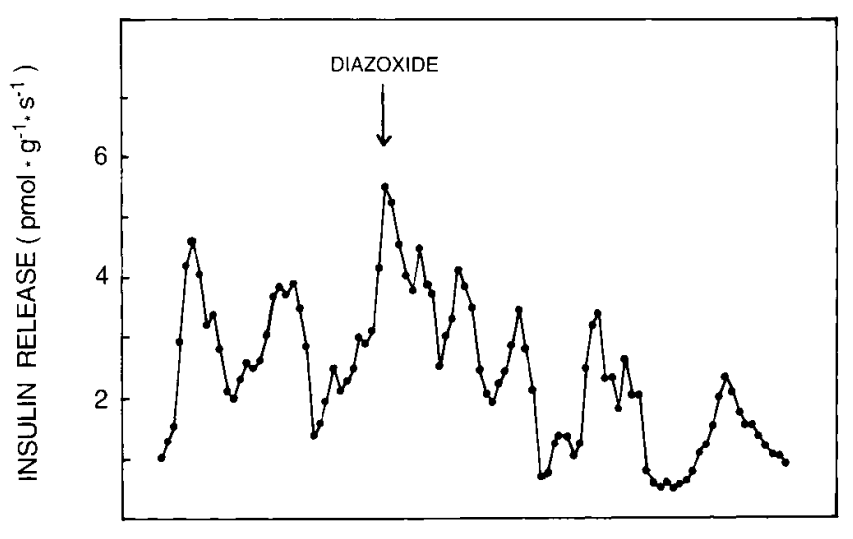

5 MIN

Figure 4. Effect of diazoxide on insulin release from an individual islet in the absence of glucose. The arrow indicates the time when 400 $\mu \mathrm{M}$ diazoxide was added to the perifusion medium. Results are representative of six experiments.

acute removal of glucose from the medium (Fig. 2) nor exposure to glucose-free medium during $150 \mathrm{~min}$ (Table I) affected the frequency of the insulin pulses.

Mathematical analysis revealed that insulin was also released in pulses when glucose-free media were supplemented with $1 \mu \mathrm{M}$ clonidine (Fig. 3) or $400 \mu \mathrm{M}$ diazoxide (Fig. 4). Clonidine, but not diazoxide, suppressed the average secretory rate (Table II). Neither clonidine nor diazoxide affected the frequency of the oscillations.

\section{Discussion}

The temporal and spatial control of many biological processes is accomplished in an oscillatory manner (13). Indeed, a number of cellular events, including exocytosis of secretory products, are subject to periodic variations. In many cases this periodicity can be accounted for by oscillations of the cytoplasmic concentration of $\mathrm{Ca}^{2+}$, a key regulator of cellular activities (14). An illustrative example of oscillatory $\mathrm{Ca}^{2+}$ signaling is the pulses of insulin release generated by a high concentration of

Table II. Insulin Release from Single Pancreatic Islets in Glucose-free Media Supplemented or Not with Clonidine or Diazoxide

\begin{tabular}{ccccc}
\hline \multicolumn{2}{c}{ Perifusion } & & \multicolumn{2}{c}{ Characteristics of insulin release } \\
\cline { 5 - 5 } Clonidine & Diazoxide & & Average rate & Frequency \\
\hline$\mu M$ & $\mu M$ & & $\mathrm{pmol} \cdot \mathrm{g}^{-1} \cdot \mathrm{s}^{-1}$ & $\mathrm{~min}^{-1}$ \\
- & - & & $3.3 \pm 0.7(12)$ & $0.40 \pm 0.03(12)$ \\
1 & - & & $0.6 \pm 0.2 *(5)$ & $0.43 \pm 0.09(5)$ \\
- & 400 & & $2.2 \pm 0.6(7)$ & $0.33 \pm 0.05(7)$
\end{tabular}

After $60 \mathrm{~min}$ of introductory perifusion with $3 \mathrm{mM}$ glucose, the release of insulin was measured during $20 \mathrm{~min}$ in a glucose-free medium in the presence or absence of clonidine and diazoxide. The measurements were started $10 \mathrm{~min}$ after the change of the media. Mean values \pm SEM for the number of experiments are shown within parenthesis. $* P<0.01$ compared with islets perifused in the absence of additives. glucose, the major physiological stimulator of the pancreatic $\beta$ cells. There is no doubt that this glucose effect involves rhythmic depolarization, resulting in periodic entry of $\mathrm{Ca}^{2+}$ via voltage-dependent $\mathrm{Ca}^{2+}$ channels (4). Since the glucose-induced depolarization is mediated by closure of ATP-sensitive $\mathrm{K}^{+}$ channels, it has been suggested that the cyclic variations of the membrane potential reflect oscillations in the metabolism of the $\beta$ cells $(15,16)$. Ample support for inherent fluctuations of the ATP production was obtained from the recent demonstration of cyclic variations in the activity of the ATP-sensitive $\mathrm{K}^{+}$ channels under conditions when the voltage-dependent $\mathrm{Ca}^{2+}$ channels are closed (17).

Glucose induces slow oscillations of cytoplasmic $\mathrm{Ca}^{2+}$ in individual $\beta$ cells, provided that the concentration of the sugar is raised above a threshold level (4). This is in contrast with the glucagon-secreting $\alpha_{2}$ cells, which are known to oscillate in the presence of $3 \mathrm{mM}$ glucose (18). The slow oscillations of cytoplasmic $\mathrm{Ca}^{2+}$ are not restricted to isolated cells but occur also in intact islets. Among a number of publications on this topic, one reports of $\left[\mathrm{Ca}^{2+}\right]_{i}$ oscillations in rat islets exposed to glucose concentrations as low as $3 \mathrm{mM}$ (16). It is tempting to speculate that this $\mathrm{Ca}^{2+}$ signal has its origin in the peripherally located $\alpha_{2}$ cells rather than in the $\beta$ cells. In the present study the risk for interference from the $\alpha_{2}$ cells was minimized by performing the analyses with islets containing a high proportion of $\beta$ cells (8). The usefulness of these islets is illustrated from the previous observation that their $\left[\mathrm{Ca}^{2+}\right]_{\mathrm{i}}$ oscillations are well correlated to glucose-induced pulses of insulin release $(6,9)$. We can now confirm that cytoplasmic $\mathrm{Ca}^{2+}$ remains at a stable low level at $3 \mathrm{mM}$ glucose in islets that respond to a raised concentration of the sugar with distinct slow oscillations of the ion.

Studies of pulsatile release of insulin from isolated islets are associated with various methodological problems (11). So far most analyses have been based on measurements of insulin from hundreds of islets without apparent functional coupling with sampling intervals of $1 \mathrm{~min}$ or more. Using such an approach, it was reported that human islets release insulin in pulses of $10 \mathrm{~min}$ both at 3.3 and $16.7 \mathrm{mM}$ glucose (19). This observation is difficult to evaluate, since measurements of the glucose-stimulated insulin release from single human islets have revealed secretory pulses as short as 3-4 min (20). In the present study advantage was taken of single large islets from $o b / o b$ mice for measuring basal insulin release with a sensitive ELISA technique. These islets contain a high proportion of $\beta$ cells (8), which have a rhythm similar to that of human $\beta$ cells both in terms of $\left[\mathrm{Ca}^{2+}\right]_{\mathrm{i}}$ oscillations (20) and variations in ATP-sensitive $\mathrm{K}^{+}$channel activity (17). When taking samples of the perifusate with 20 -s intervals, it was found that basal insulin release is pulsatile. The duration of the pulses was 2-3 min, which is equivalent to what is seen when single islets from $o b / o b$ mice or rats are exposed to a raised glucose concentration (11). Accordingly, basal insulin release differs from that obtained during glucose stimulation only with respect to the amplitude of the pulses generated.

The principal message of the present study is that intact pancreatic islets have a pulsatile insulin release when exposed to a low concentration of glucose or even a medium lacking the sugar. These pulses occurred in the absence of the concomitant fluctuations of $\left[\mathrm{Ca}^{2+}\right]_{\mathrm{i}}$ seen during conditions known to stimulate $\mathrm{Ca}^{2+}$ entry into $\beta$ cells $(6,9)$. The discovery that basal release of insulin from an isolated islet is rhythmic raises the question of whether periodic variations of signals other 
than $\mathrm{Ca}^{2+}$ can generate insulin pulses. This may well be the case, since insulin release is known to depend not only on variations in $\mathrm{Ca}^{2+}$ but also on the sensitivity of the secretory machinery to this ion (21). In analogy to what has been proposed for neuroendocrine cells, we have reasons to believe that the secretion of insulin is a two-step process, where cyclic AMP and ATP act together with $\mathrm{Ca}^{2+}$ to facilitate the initial attachment of the secretory granules to the plasma membrane (22). Rhythmic release of glucagon from adjacent $\alpha_{2}$ cells may well account for generation of cAMP-dependent pulses of basal insulin release. In the present study, prolonged exposure to the $\alpha_{2}$ adrenergic agonist clonidine, which suppresses the formation of cyclic AMP in the $\beta$ cells (23), resulted in a significant lowering of the insulin pulses. Moreover, it is characteristic for glucagon-producing $\alpha_{2}$ cells to have oscillatory $\left[\mathrm{Ca}^{2+}\right]_{i}$ in the presence of low concentrations of glucose (18).

The alternative, that variations in the energy metabolism are responsible for the pulsatility of basal insulin release, is consistent with previous observations of cyclic variations of the ATP-sensitive $\mathrm{K}^{+}$channels in nonstimulated $\beta$ cells (17). Actually, the periodic variations of the channel activity in mouse $\beta$ cells exposed to $0-3 \mathrm{mM}$ glucose were almost the same as those observed for insulin release. There are reasons to believe that the generation of the insulin pulses in unstimulated $\beta$ cells does not result from periodic variations of the $\mathrm{K}^{+}$permeability but reflects a direct participation of ATP in the secretory process. Accordingly, pulsatile insulin release was also seen in the presence of diazoxide, a compound which hyperpolarizes $\beta$ cells by opening their ATP-sensitive $\mathrm{K}^{+}$channels (24).

The present study demonstrates pulsatile release of insulin from isolated nonstimulated pancreatic islets. This observation makes it easy to understand why there are also cyclic variations in the circulating insulin in the fasting state $(1,2,7)$. An interesting aspect of the insulin cycles is the loss of their regular appearance before the development of type 2 diabetes (25). It should be a matter for further studies to decide whether this can be attributed to a primary disturbance of the ATP production in the $\beta$ cells.

\section{Acknowledgments}

The authors are grateful to Kristina Mustajärvi and Else-Marie Andersson for their skillful technical assistance.

This study was supported by grants from the Swedish Medical Research Council (12X-562 and 12X-11203), the Novo Nordisk Foundation, the Swedish Diabetes Association, and the Family Ernfors Foundation.

\section{References}

1. Jaspan, P.J., E. Lever, K.S. Polonsky, and E. Van Cauter. 1986. In vivo pulsatility of pancreatic islet peptides. Am. J. Physiol. 251:E215-E226.

2. Lefebvre, P.J., G. Paolisso, A.J. Scheen, and J.C. Henquin. 1987. Pulsatility of insulin and glucagon release: physiological significance and pharmacological implications. Diabetologia. 30:433-452.
3. Grapengiesser, E., E. Gylfe, and B. Hellman. 1988. Glucose-induced oscillations of cytoplasmic $\mathrm{Ca}^{2+}$ in the pancreatic $\beta$-cell. Biochem. Biophys. Res. Commun. 151:1299-1304

4. Hellman, B., E. Gylfe, E. Grapengiesser, P.E. Lund, and A. Berts. 1992. Cytoplasmic $\mathrm{Ca}^{2+}$ oscillations in pancreatic $\beta$-cells. Biochim. Biophys. Acta. 1113:295-305

5. Gylfe, E., E. Grapengiesser, and B. Hellman. 1991. Propagation of cytoplasmic $\mathrm{Ca}^{2+}$ oscillations in clusters of pancreatic $\beta$-cells exposed to glucose. Cell Calcium. 12:229-240.

6. Bergsten, P., E. Grapengiesser, E. Gylfe, A. Tengholm, and B. Hellman. 1994. Synchronous oscillations of cytoplasmic $\mathrm{Ca}^{2+}$ and insulin release in glucose-stimulated pancreatic islets. J. Biol. Chem. 269:8749-8753.

7. Porksen, N., S. Munn, J. Steers, S. Vore, J. Veldhuis, and P. Butler. 1995. Pulsatile insulin secretion accounts for $70 \%$ of total insulin secretion during fasting. Am. J. Physiol. 269:E478-E488.

8. Hellman, B. 1965. Studies in obese-hyperglycemic mice. Ann. NY Acad. Sci. 131:541-558.

9. Bergsten, P. 1995. Slow and fast oscillations of cytoplasmic $\mathrm{Ca}^{2+}$ in pancreatic islets correspond to pulsatile insulin release. Am. J. Physiol. 268:E282E287.

10. Grynkiewicz, G., M. Poenie, and R.Y. Tsien. 1985. A new generation of $\mathrm{Ca}^{2+}$ indicators with greatly improved fluorescence properties. J. Biol. Chem. 260:3440-3450.

11. Bergsten, P., and B. Hellman. 1993. Glucose-induced amplitude regulation of pulsatile insulin secretion from individual pancreatic islets. Diabetes. 42: 670-674.

12. Bergsten, P., and B. Hellman. 1993. Glucose-induced cycles of insulin release can be resolved into distinct periods of secretory activity. Biochem. Biophys. Res. Commun. 192:1182-1188.

13. Berridge, M.J., and G. Dupont. 1994. Spatial and temporal signalling by calcium. Curr. Biol. 6:267-274.

14. Clapham, D.E. 1995. Calcium signalling. Cell. 80:259-268.

15. Corkey, B.E., K. Tornheim, J.T. Deeney, M.C. Glennon, J.C. Parker, F.M. Matchinsky, N.B. Ruderman, and M. Prentki. 1988. Linked oscillations of free calcium and the ATP/ADP ratio in permeabilized RINm5F insulinoma cells supplemented with a glycolyzing cell-free muscle extract. J. Biol. Chem. 263:4254-4258.

16. Longo, E.A., K. Tornheim, J.T. Deeney, B.A. Varnum, D. Tillotson, M. Prentki, and B.E. Corkey. 1991. Oscillations in cytosolic free $\mathrm{Ca}^{2+}$, oxygen consumption and insulin release in glucose-stimulated rat pancreatic islets. J. Biol. Chem. 266:9314-9319.

17. Dryselius, S., P.E. Lund, E. Gylfe, and B. Hellman. 1994. Variations in ATP-sensitive $\mathrm{K}^{+}$channel activity provide evidence for inherent metabolic oscillations in pancreatic $\beta$-cells. Biochem. Biophys. Res. Commun. 205:880-885.

18. Berts, A., E. Gylfe, and B. Hellman. 1995. $\mathrm{Ca}^{2+}$ oscillations in pancreatic islet cells secreting glucagon and somatostatin. Biochem. Biophys. Res. Commun. 208:644-649.

19. Marchetti, P., D.W. Sharp, M. Mclear, R. Gingerich, E. Finke, B. Olack, C. Swanson, R. Giannarelli, R. Navalesi, and P.E. Lacy. 1994. Pulsatile insulin secretion from isolated human pancreatic islets. Diabetes. 43:827-830.

20. Hellman, B., E. Gylfe, P. Bergsten, E. Grapengiesser, P.E. Lund, A. Berts, A. Tengholm, D.G. Pipeleers, and Z. Ling. 1994. Glucose induces oscillatory $\mathrm{Ca}^{2+}$ signalling and insulin release in human pancreatic $\beta$-cells. Diabetologia. 37(Suppl. 2):S11-S20.

21. Hellman, B., E. Gylfe, E. Grapengiesser, P.E. Lund, and A. Marcström. 1992. Cytoplasmic calcium and insulin secretion. In Nutrient Regulation of Insulin Secretion. P.R. Flatt, editor. Portland Press Ltd., London, UK. 213-246.

22. Hellman, B., E. Gylfe, P. Bergsten, E. Grapengiesser, P.E. Lund, A Berts, S. Dryselius, A. Tengholm, Y.J. Liu, M. Eberhardsson, and R.H Chow. 1994. The role of $\mathrm{Ca}^{2+}$ in the release of pancreatic islet hormones. Diabete \& Metab. 20:123-131.

23. Garcia-Morales, P., S.P. Dufrane, A. Sener, I. Valverde, and W.J. Malaisse. 1984. Inhibitory effect of clonidine upon adenylate cyclase activity, cyclic AMP production and insulin release in rat pancreatic islets. Biosci. Rep. 4:511521.

24. Panten, U., J. Burgfeld, F. Goerke, M. Rennicke, M. Schwanstecher, A. Wallasch, B.J. Zünkler, and S. Lenzen. 1989. Control of insulin secretion of sulphonylureas, meglitinide and diazoxide in relation to their binding to the sulfonylurea receptor in pancreatic islets. Biochem. Pharmacol. 38:1217-1229.

25. O'Rahilly, S., R.C. Turner, and D.R. Matthews. 1988. Impaired pulsatile secretion of insulin in relatives of patients with non-insulin-dependent diabetes. N. Engl. J. Med. 318:1225-1230. 